\title{
Leaf Area Determination for Sesame (Sesamum indicum), Wheat (Triticum aestivuma), Groundnut (Arechis hypogaea) and Bambaranut (Vigna subterrane) Crops Using Linear Measurements
}

\author{
MUSA, UMAR TANKO ${ }^{1 *}$ YUSUF, MOMOHJIMOH ${ }^{2}$ OJO, SAMUEL OLUWASEUN ${ }^{3}$ \\ Department of Crop Production, Kogi State University, P.M.B. 1008, Anyigba, Nigeria
}

\begin{abstract}
This study was carried out within the green house environment of the Faculty of Agriculture, Kogi State University (Latitude $7^{\circ} .6^{1} \mathrm{~N}$ and Longitude $7^{\circ} .43^{1} \mathrm{E}$ ) Anyigba in the Southern Guinea Savannah agro ecological zone of Nigeria during 2016 raining season. The experiment was laid using Randomized complete block design with 8 replicates. The treatment consisted of sesame, groundnut, wheat and bambaranut. Each treatment was repeated eight times, the results reveal K-coefficient for determination of leaf area to be $0.43,0.62,0.53$ and 0.64 for sesame, groundnut, wheat and bambaranut respectively. The use of multiple regression equation improves the prediction over linear measurement. Also, simple and multiple regression analysis was carried out in other to increase precision in use of leaf area in the four treatments which are; sesame $\left(\mathrm{Y}=1563.632+0.409 \mathrm{x}_{1}, \mathrm{Y}=1563.632+\right.$ $\left.0.409 \mathrm{x}_{1}-45.73 \mathrm{x}_{2}\right)$, groundnut $\left(\mathrm{Y}=-3175.794+0.611 \mathrm{x}_{1}, \mathrm{Y}=3175.794+0.611 \mathrm{x}_{1}+56.825 \mathrm{x}_{2}\right)$, wheat $(\mathrm{Y}=$ $\left.376.084+0.265 \mathrm{x}_{1}, \mathrm{Y}=376.084+0.265 \mathrm{x}_{1}-4.559 \mathrm{x}_{2}\right)$ and bambaranut $\left(\mathrm{Y}=162.603+0.615 \mathrm{x}_{1}, \mathrm{Y}=162.603+0.615 \mathrm{x}_{1}\right.$ $\left.+15.677 \mathrm{x}_{2}\right)$. The data on leaf area and leaf number value of all the four crops were fitted into linear regression analysis separately as well as combined data, it shows significant difference or improvement over the use of linear measurement
\end{abstract}

Keywords: K-Coefficient, Linear measurements, Simple and Multiple regression of Sesame, Wheat, Groundnut and Bambaranut.

DOI: $10.7176 / \mathrm{JBAH} / 10-12-04$

Publication date: June $30^{\text {th }} 2020$

\section{INTRODUCTION}

Leaf is an important plant organ, and is associated with photosynthesis evapotranspiration; therefore, leaf area measurements are required in most physiological and agronomic studies involving plant growth (Guo \& Sun, 2001). Estimation of leaf area is an essential component of plant growth analysis and evapo-transpirational studies. Leaf area is important for crop light interception and therefore has a large influence on growth (Boote et al., 1988), transpiration (Enoch and Hurd, 1979) and growth rate (Leith et al., 1986).

Leaf area production is essential for energy transfer and dry matter accumulation processes in crop canopies. It is also useful in the analysis of canopy architecture as it allows determination of leaf area index, which is important for light interception, radiation use efficiency, plant growth, etc. However, measurement of leaf area of all the leaves of any single plant is not only time consuming but also involves a large amount of labour. But, one cannot do away without measuring leaf area because estimation of leaf area is an essential part of plant growth analysis. Estimation of leaf area from mathematical models involving linear measurements of leaf is relatively accurate and non-destructive.

A mathematical model can be obtained by correlating the leaf length (L), width (W) or length $\mathrm{x}$ width (LxW) to the actual leaf area (LA) of a sample of leaves using regression analysis. Although, several prediction models are available to estimate leaf area for numerous crops. Montgomery, 1911 first suggested that leaf area of a plant can be calculated from linear measurement of leaves using a general relationship: -

$\mathrm{A}=\mathrm{b} \times$ length $\mathrm{x}$ max width,

Where; $b$ is a coefficient.

Destructive and non-destructive methods have been employed in the measurements of leaf area over the years. The non-destructive approach gives the possibility to follow the same plants through the vegetative period; which is particularly important when the plot size is very small and the growth is dynamic. These methods usually save time, allowing successive measurements on the leaves without causing damage to the leaf crop (Rouphael et al 2006). This method is also based on linear measurements and is quicker and easier to be executed. it presents good precision for the study of plant growth in several crops (Manivel \& Weaver, 1974; Sepaskhah, 1977; Robbins \& Pharr, 1987; Silva et al., 1998; Gutiérrez \& Lavín, 2000; Astegiano et al., 2001; Guo \& Sun, 2001).

Researches with plants cultivated in pots are common under greenhouse conditions because less space is required and the number of treatments and replications can be quite increased. Under pot cultivation, a nondestructive method for LAI evaluation is required with the advantage that the same plant can be measured several times during the growing period, thus leading to a more real curve of LAI increase along the growing season. The 
use of linear measurements is flexible and has been applied to a wide variety of crops (Montgomery,1911) to Ocimumviridis (Abani,1988). These procedures have proved to be reliable and they correlated well with measurements made using traces on graph sheet or leaf meters. Until area meters become cheap and common place, non-destructive linear measurement remains an important procedure in the estimation of leaf area. Therefore, this study was carried out to determine;

1. Leaf area for sesame, wheat, ground nut and bambaranut, using;

a. Linear measurements,

b. Graph methods

c. Linear regression models;

2. K-coefficients for correcting errors inherent in leaf area determination using linear measurements.

3. Comparison of K-coefficients from the four crops using standard error.

\section{MATERIALS AND METHODS}

\subsection{Experimental Location}

The experiment was conducted in green house located within in faculty of Agriculture Kogi State University Anyigba, (Latitude 70.61N and Longitude 70.431E) Kogi State which falls within the southern guinea savannah zone of Nigeria.

\subsection{Experimental Design and Treatments}

Treatment consists of four crops: Sesame (Sesamum indicium), wheat (Triticum aestivuma), groundnut (Arechis hypogaea) and bambaranut (Vigna subterrane), were used for the experiment. Seeds were obtained from Agriculture Development Programme (ADP) Anyigba. Each treatment was replicated eight times, giving a total of Thirty-two (32) pots. 20-21liters capacity, perforated bucket were half filled with top soil these large buckets were used so as to allow for full growth of the crops. This experiment was laid out in front of the glasshouse using Completely Randomized Design (CRD)

\subsection{Planting, Watering and Weeding}

Eight seeds of the randomized crops were sowed per pot at $2 \mathrm{~cm}$ depth making a total 256 seeds (i.e sesame, wheat, groundnut and Bambaranut) and later thinned to 5 stand per pot. Watering was done every three days to allow for luxuriant growth of the foliage. Weeding was done by hand pulling method.

\subsection{Data Collection}

a. Seedlings emergence was determined by counting the number seedling that emerges 3-4 days after planting depending the sprouting days required for each crop.

b. Number of leaves per plants was determined by visual count of the leaves of the plants per pots.

c. Leaf Tracing Methods: this involves detachment of leaf which was drawn on graph paper and its area measured by counting the surface or dots within the leaf outline one plant/pot and for every crop harvested at 3,6,9 and 12 weeks after planting. The leaves were carefully plucked and placed on a graph paper and traced out; the total leaf area was therefore determined by counting the number of square $\left(1 \mathrm{~cm}^{2}\right)$ that fell within the leaf surface. For incomplete square areas, estimates were made using "cut and fill" methods as is done in land survey (Kuetand Marshall, 1971). This is one of earliest methods for determining leaf area and has been used extensively to calibrate all other methods.

d. Leaf area $\left(\mathrm{cm}^{2}\right)$ : This was calculated as the product of the total length and breadth at the broadcast point of the longest leaf on the plant i.e. leaf Area = Lamina length $\mathrm{x}$ Maximum width $\mathrm{x} \mathrm{K}$ (where $\mathrm{k}$ is the coefficient to be derived)

e. Plant height (cm) at 3, 6, 9 and 12 weeks after sowing and at maturity was done by measuring heights of 4 plant from ground level to the tip of epical leaves.

\subsection{STATISTICAL ANALYSIS}

All data collected were subjected to regression analysis using simple and multiple regression model. The standard error and coefficient of determined was also determined for each data and for each crops.

\section{RESULTS}

\subsection{Linear Measurements and Graph Method}

Determination of K-Coefficient Using Ratios of Linear Measurement to Graph Method

K-coefficient using the ratio of linear measurement to graph determination at 3,6,9, and 12weeks for Sesame, groundnut, wheat and bambaranut respectively were carried out appropriately during the period of the experiment as shown in tables 1, 2, $3 \& 4$.

K-coefficient for sesame varies between $0.42-0.50$. However, the average value obtained over four sampling 
periods was 0.464 , groundnut's k-coefficient value varies between $0.60-0.64$ for all the period of sampling, the average k-value obtained was 0.62 for $3,6,9$, and 12 weeks sampling period respectively, $\mathrm{k}$-value for wheat varies between $0.51-0.55$, with an average value of $0.53,0.55,0.53,0.53$ for $3,6,9$ and 12 weeks respectively sampling periods. Lastly, k-coefficient for bambaranut varies between 0.59-0.65 with an average value of 0.64 (table 5).

\subsection{Coefficient determination of leaf area $(k)$}

K-Value for Sesame, Groundnut, Wheat and Bambaranut.

$\mathrm{K}$-values for sesame, groundnut, wheat, and bambaranut and their standard error (SE) values are presented in table 5 , the lowest $\mathrm{k}$-value of $0.46 \pm 0.04$ was obtained for sesame, $0.53 \pm 0.06$ for wheat, $0.62 \pm 0.01$ for groundnut, and $0.64 \pm 0.02$ for bambaranut respectively.

\subsection{Simple and Multiple Regression}

Prediction of leaf area of Sesame, Groundnut, Wheat and Bambaranut using multiple regression in Anyigba Actual leaf area predicted for sesame, groundnut, wheat and bambaranut using simple and multiple regressions respectively are presented in table 6 . The coefficient of determination $\left(\mathrm{R}^{2}\right)$ for the 4 crops and for the prediction equation of the four crops are $0.861,0.991,0.940$ and 0.981 respectively (table 18).

Table 1: Determination of $k$-coefficients and Leaf area of sesame, groundnut, wheat, and bambaranut using graph and linear measurement ratio at 3 weeks after sowing, Anyigba, Kogi State.

\begin{tabular}{|c|c|c|c|c|c|c|c|}
\hline Pots/plots & $\begin{array}{l}\text { No of } \\
\text { Leaves }\end{array}$ & $\mathrm{L} \times \mathrm{B}(\mathrm{cm} 2)$ & Graph(cm2) & $\begin{array}{l}\text { Average L } \mathrm{x} \\
\mathrm{B}(\mathrm{cm} 2)\end{array}$ & $\begin{array}{l}\text { Average } \\
\text { graph }(\mathrm{cm} 2)\end{array}$ & $\begin{array}{l}\text { Dry } \\
\text { (g) }\end{array}$ & weight \\
\hline 1 Sesame & 8 & 504.29 & 210 & 63.04 & 26.25 & 0.20 & \\
\hline 2 Groundnut & 41 & 5858.55 & 3600.29 & 142.89 & 87.81 & 0.34 & \\
\hline 3 Wheat & 6 & 189.05 & 21.50 & 31.51 & 15.25 & 0.13 & \\
\hline 4 Bambaranut & 25 & 6724.60 & 4320.50 & 268.98 & 172.82 & 1.08 & \\
\hline 5 Sesame & 7 & 448.89 & 202 & 64.13 & 28.86 & 0.18 & \\
\hline 6 Groundnut & 40 & 4283.29 & 2680 & 107.08 & 67.00 & 0.32 & \\
\hline 7 Wheat & 5 & 173.57 & 98 & 34.71 & 19.60 & 0.12 & \\
\hline 8 Bambaranut & 29 & 9267.23 & 5802 & 319.56 & 200.07 & 0.88 & \\
\hline 9 Groundnut & 36 & 7570.64 & 4720.42 & 210.30 & 131.12 & $0 . ; 35$ & \\
\hline 10 Wheat & 6 & 179.34 & 87.50 & 29.89 & 14.13 & 0.13 & \\
\hline 11 Bambaranut & 25 & 5272.66 & 3440.50 & 210.91 & 137.62 & 0.96 & \\
\hline 12 Sesame & 9 & 543.24 & 222 & 60.36 & 24.67 & 0.26 & \\
\hline 13 Groundnut & 34 & 6290.32 & 3821.50 & 185.01 & 112.40 & 0.31 & \\
\hline 14 Wheat & 6 & 167.06 & 107.50 & 27.84 & 17.92 & 0.13 & \\
\hline 15 Bambaranut & 27 & 9616.07 & 5710.50 & 356.15 & 211.50 & 0.92 & \\
\hline 16 Sesame & 8 & 455.78 & 252.50 & 56.97 & 31.56 & 0.21 & \\
\hline 17 Wheat & 5 & 235.94 & 83.50 & 47.19 & 16.70 & 0.15 & \\
\hline 18 Bambaranut & 30 & 3577.23 & 2332.50 & 119.24 & 77.75 & 1.10 & \\
\hline 19 Sesame & 8 & 534.90 & 300 & 66.86 & 37.50 & 0.25 & \\
\hline 20 Groundnut & 43 & 5191.04 & 3220.51 & 120.72 & 74.90 & 0.46 & \\
\hline 21 Wheat & 5 & 155.61 & 86.50 & 31.12 & 17.30 & 0.15 & \\
\hline 22 Bambaranut & 25 & 9527.60 & 6283.50 & 381.10 & 251.34 & 0.96 & \\
\hline 23 Sesame & 9 & 315.40 & 122.50 & 35.04 & 13.61 & 0.28 & \\
\hline 24 Groundnut & 39 & 5699.47 & 3591.27 & 146.14 & 92.08 & 0.32 & \\
\hline 25 Bambaranut & 25 & 8030.94 & 5326.50 & 321.24 & 213.06 & 0.81 & \\
\hline 26 Sesame & 6 & 559.43 & 247 & 55.94 & 41.16 & 0.15 & \\
\hline 27 Groundnut & 38 & 4119.57 & 2674.50 & 108.41 & 70.38 & 0.30 & \\
\hline 28 Wheat & 6 & 164.61 & 91 & 27.44 & 15.17 & 0.14 & \\
\hline 29 Bambaranut & 30 & 7124.42 & 4342.50 & 237.48 & 144.75 & 0.95 & \\
\hline 30 Sesame & 7 & 459.49 & 227 & 65.64 & 32.43 & 0.24 & \\
\hline 31 Groundnut & 38 & 4823.78 & 2877.50 & 126.94 & 75.72 & 0.42 & \\
\hline 32 Wheat & 6 & 156.62 & 92.50 & 26.10 & 15.42 & 0.16 & \\
\hline
\end{tabular}


Table 2: Determination of k-coefficients and Leaf area of sesame, groundnut, wheat, and bambaranut using graph and linear measurement ratio at 6 weeks after sowing, Anyigba, Kogi State.

\begin{tabular}{|c|c|c|c|c|c|c|}
\hline Pots/plots & $\begin{array}{l}\text { No of } \\
\text { leaves }\end{array}$ & $\mathrm{L} \times \mathrm{B}\left(\mathrm{cm}^{2}\right)$ & Graph $(\mathrm{cm} 2)$ & $\begin{array}{l}\text { Average L x } \\
\mathrm{B}\left(\mathrm{cm}^{2}\right)\end{array}$ & $\begin{array}{l}\text { Average } \\
\text { graph }\left(\mathrm{cm}^{2}\right)\end{array}$ & $\begin{array}{l}\text { Dry } \\
\text { weight } \\
\text { (g) }\end{array}$ \\
\hline 1 Sesame & 18 & 3403.96 & 1417.50 & 189.11 & 78.75 & 1.35 \\
\hline 2 Groundnut & 59 & 34978.99 & 21494.12 & 592.86 & 364.31 & 2.03 \\
\hline 3 Wheat & 8 & 552.61 & 267.46 & 69.08 & 33.43 & 0.38 \\
\hline 4 Bambaranut & 55 & 18617.18 & 11961.38 & 338.49 & 217.48 & 2.99 \\
\hline 5 Sesame & 15 & 3466.43 & 1559.89 & 231.10 & 103.99 & 1.39 \\
\hline 6 Groundnut & 60 & 21684.16 & 13567.50 & 361.40 & 226.13 & 1.62 \\
\hline 7 Wheat & 8 & 564.10 & 318.50 & 70.51 & 39.81 & 0.39 \\
\hline 8 Bambaranut & 58 & 31276.90 & 19581.75 & 539.26 & 337.60 & 2.9766 \\
\hline 9 Groundnut & 66 & 41962.98 & 26164.61 & 635.80 & 396.43 & 1.94 \\
\hline 10 Wheat & 7 & 510.43 & 249.04 & 72.92 & 35.58 & 0.37 \\
\hline 11 Bambaranut & 55 & 16751.68 & 10930.76 & 304.58 & 198.74 & 0.05 \\
\hline 12 Sesame & 14 & 3092.29 & 1263.69 & 220.88 & 90.26 & 1.48 \\
\hline 13 Groundnut & 59 & 39365.23 & 23915.19 & 667.21 & 405.34 & 1.94 \\
\hline 14 Wheat & 6 & 501.18 & 322.50 & 83.53 & 53.75 & 0.39 \\
\hline 15 Bambaranut & 52 & 34910.52 & 20731.60 & 671.36 & 398.69 & 3.34 \\
\hline 16 Sesame & 17 & 2365.72 & 1310.60 & 139.16 & 77.09 & 1.09 \\
\hline 17 Wheat & 7 & 456.15 & 161.43 & 65.16 & 23.06 & 0.29 \\
\hline 18 Bambaranut & 60 & 9886.16 & 6446.18 & 164.77 & 107.44 & 3.04 \\
\hline 19 Sesame & 16 & 2503.33 & 1404 & 156.46 & 87.75 & 1.17 \\
\hline 20 Groundnut & 56 & 20764.16 & 12882.04 & 370.79 & 230.04 & 1.84 \\
\hline 21 Wheat & 8 & 414.96 & 230.67 & 51.87 & 28.83 & 0.40 \\
\hline 22 Bambaranut & 53 & 26895.62 & 17737.80 & 507.46 & 334.68 & 2.71 \\
\hline 23 Sesame & 16 & 1317.92 & 511.88 & 82.37 & 31.99 & 1.17 \\
\hline 24 Groundnut & 58 & 24580.10 & 15957.85 & 423.80 & 275.14 & 1.79 \\
\hline 25 Bambaranut & 52 & 24588.56 & 16308.30 & 472.86 & 313.62 & 2.48 \\
\hline 26 Sesame & 13 & 4400.85 & 1943.07 & 338.53 & 149.47 & 1.18 \\
\hline 27 Groundnut & 54 & 34018.71 & 21435.39 & 629.98 & 396.95 & 1.91 \\
\hline 28 Wheat & 7 & 446.80 & 247 & 63.83 & 35.29 & 0.3 \\
\hline 29 Bambaranut & 52 & 19423.42 & 11839.03 & 373.53 & 227.67 & 2.59 \\
\hline 30 Sesame & 18 & 2125.14 & 1049.88 & 118.06 & 58.33 & 1.11 \\
\hline 31 Groundnut & 58 & 23314.94 & 13907.92 & 401.98 & 239.79 & 2.03 \\
\hline 32 Wheat & 8 & 352.40 & 208.13 & 44.05 & 26.02 & 0.36 \\
\hline
\end{tabular}

Table 3: Determination of $k$-coefficients and Leaf area of sesame, groundnut, wheat, and bambaranut using graph and linear measurement ratio at 9 weeks after sowing, Anyigba, Kogi State.

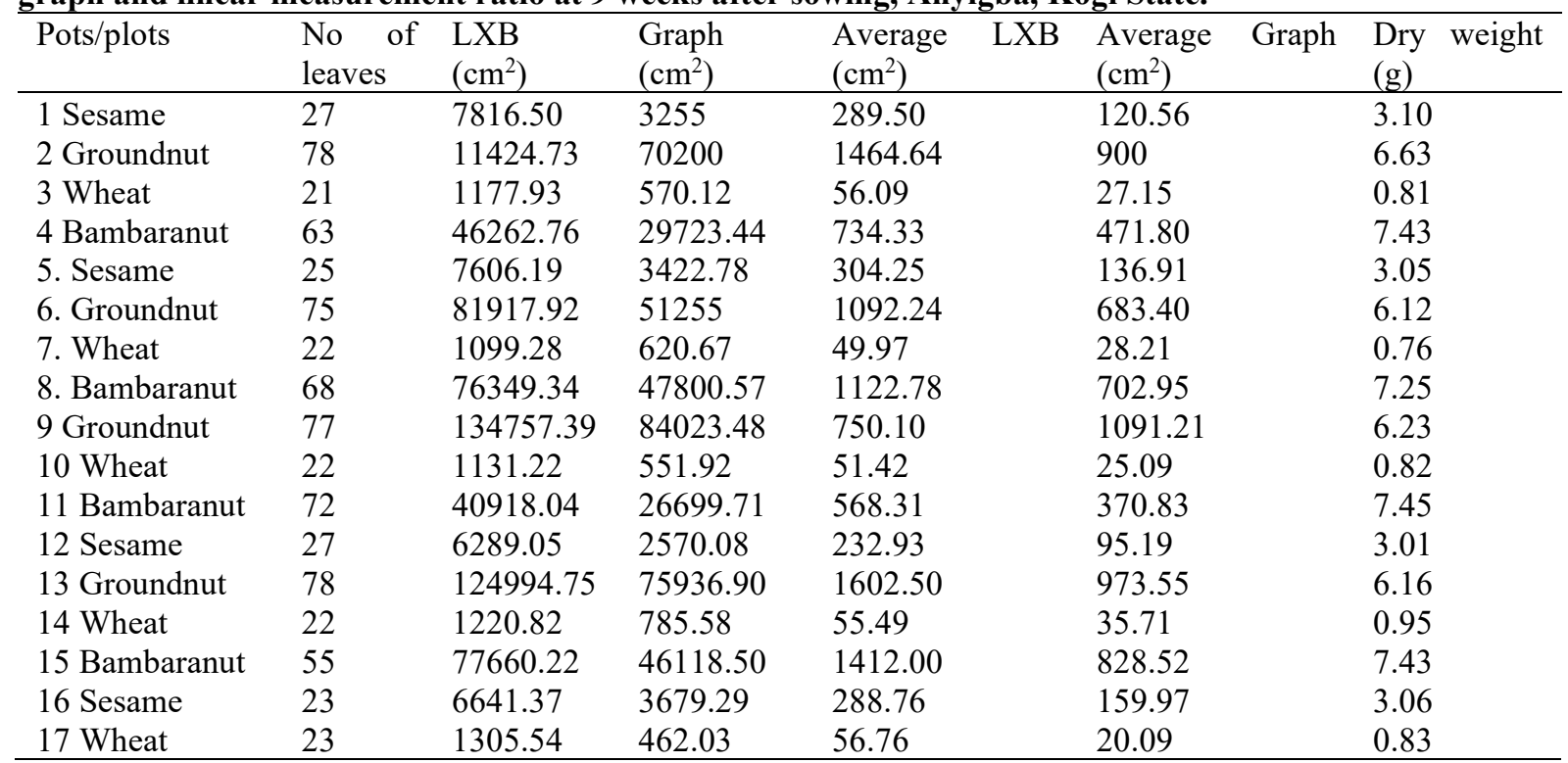




\begin{tabular}{|c|c|c|c|c|c|c|}
\hline Pots/plots & $\begin{array}{l}\text { No of } \\
\text { leaves }\end{array}$ & $\begin{array}{l}\mathrm{LXB} \\
\left(\mathrm{cm}^{2}\right)\end{array}$ & $\begin{array}{l}\text { Graph } \\
\left(\mathrm{cm}^{2}\right)\end{array}$ & $\begin{array}{l}\text { Average } \\
\left(\mathrm{cm}^{2}\right)\end{array}$ & $\begin{array}{l}\text { Average Graph } \\
\left(\mathrm{cm}^{2}\right)\end{array}$ & $\begin{array}{l}\text { Dry weight } \\
(\mathrm{g})\end{array}$ \\
\hline 18 Bambaranut & 59 & 24097.52 & 15712.57 & 408.43 & 266.32 & 7.41 \\
\hline 19 Sesame & 27 & 6589.97 & 3696 & 244.07 & 136.89 & 3.08 \\
\hline 20 Groundnut & 72 & 73464.50 & 45577.22 & 1020.34 & 633.02 & 6.51 \\
\hline 21 Wheat & 20 & 829.92 & 461.33 & 41.50 & 23.07 & 0.80 \\
\hline 22 Bambaranut & 55 & 68876.61 & 45424.47 & 1252.30 & 825.90 & 6.94 \\
\hline 23 Sesame & 26 & 3514.46 & 1365 & 135.17 & 52.50 & 3.12 \\
\hline 24 Groundnut & 74 & 85824.38 & 55718.75 & 1159.79 & 752.96 & 6.25 \\
\hline 25 Bambaranut & 63 & 70692.10 & 46886.35 & 1122.10 & 744.23 & 7.13 \\
\hline 26 Sesame & 22 & 11673.44 & 5154.07 & 530.61 & 234.28 & 3.13 \\
\hline 27 Groundnut & 71 & 116304.81 & 73284.35 & 1638.10 & 1032.17 & 6.53 \\
\hline 28 Wheat & 25 & 964.14 & 533 & 38.57 & 21.32 & 0.82 \\
\hline 29 Bambaranut & 67 & 53245.67 & 32454.47 & 794.71 & 484.40 & 7.10 \\
\hline 30 Sesame & 28 & 5992.52 & 2960.46 & 214.02 & 105.73 & 3.13 \\
\hline 31 Groundnut & 67 & 75917.11 & 45286.37 & 1133.09 & 675.92 & 6.61 \\
\hline 32 Wheat & 22 & 822.26 & 485.63 & 37.38 & 22.07 & 084 \\
\hline
\end{tabular}

Table 4: Determination of k-coefficients and Leaf area of sesame, groundnut, wheat, and bambaranut using graph and linear measurement ratio at 12 weeks after sowing, Anyigba, Kogi State.

\begin{tabular}{|c|c|c|c|c|c|c|}
\hline Pots/plots & $\begin{array}{l}\text { No of } \\
\text { leaves }\end{array}$ & $\operatorname{LXB}\left(\mathrm{cm}^{2}\right)$ & Graph $\left(\mathrm{cm}^{2}\right)$ & $\begin{array}{l}\text { Average } \\
\text { LXB }\left(\mathrm{cm}^{2}\right)\end{array}$ & $\begin{array}{l}\text { Average } \\
\text { Graph } \\
\left(\mathrm{cm}^{2}\right)\end{array}$ & $\begin{array}{l}\text { Dry weight } \\
\text { (g) }\end{array}$ \\
\hline 1 Sesame & 32 & 18961.30 & 7896 & 592.54 & 246.75 & 7.52 \\
\hline 2 Groundnut & 83 & 108038.55 & 66396.58 & 1301.67 & 799.92 & 6.27 \\
\hline 3 Wheat & 25 & 3315.65 & 1604.77 & 132.63 & 64.19 & 2.28 \\
\hline 4 Bambaranut & 86 & 95887.82 & 61607.13 & 1114.98 & 716.36 & 15.40 \\
\hline 5. Sesame & 40 & 15785.97 & 7103.67 & 394.65 & 177.59 & 6.33 \\
\hline 6. Groundnut & 80 & 89319.19 & 59378.45 & 1123.51 & 742.23 & 7.09 \\
\hline 7. Wheat & 24 & 2965.15 & 1674.17 & 123.55 & 69.76 & 2.05 \\
\hline 8. Bambaranut & 91 & 156489.82 & 97974.68 & 1719.67 & 1076.65 & 14.86 \\
\hline 9 Groundnut & 82 & 145788.90 & 90901.80 & 1777.91 & 1108.56 & 6.74 \\
\hline 10 Wheat & 26 & 3186.73 & 1554.81 & 124.97 & 60.97 & 2.31 \\
\hline 11 Bambaranut & 91 & 86175.04 & 56230.67 & 946.98 & $617.92^{\prime}$ & 15.69 \\
\hline 12 Sesame & 42 & 12954.19 & 5293.85 & 312.15 & 126.04 & 6.20 \\
\hline 13 Groundnut & 80 & 1248532.72 & 90236.71 & 1856.66 & 1127.96 & 7.32 \\
\hline 14 Wheat & 23 & 2968.53 & 1910.19 & 129.07 & 83.05 & 2.31 \\
\hline 15 Bambaranut & 75 & 147167.68 & 87395.48 & 1962.24 & 1165.27 & 14.08 \\
\hline 16 Sesame & 36 & 14476.44 & 8019.88 & 402.12 & 222.78 & 6.67 \\
\hline 17 Wheat & 24 & 3759.31 & 1330.43 & 156.64 & 55.44 & 2.39 \\
\hline 18 Bambaranut & 81 & 49040.57 & 31976.46 & 605.44 & 394.77 & 15.08 \\
\hline 19 Sesame & 41 & 16410.73 & 9704 & 400.26 & 224.49 & 7.67 \\
\hline 20 Groundnut & 77 & 65452.24 & 40606.43 & 855.59 & 527.36 & 5.80 \\
\hline 21 Wheat & 23 & 2552.00 & 1418.60 & 133.42 & 63.05 & 2.46 \\
\hline 22 Bambaranut & 82 & 136463.02 & 89998.05 & 1664.18 & 1097.54 & 13.75 \\
\hline 23 Sesame & 40 & 8245.46 & 3202.50 & 206.14 & 80.06 & 7.32 \\
\hline 24 Groundnut & 83 & 85549.74 & 55540.45 & 1036.97 & 669.16 & 6.23 \\
\hline 25 Bambaranut & 81 & 144556.92 & 95877 & 1784.65 & 1183.67 & 14.58 \\
\hline 26 Sesame & 35 & 21855.07 & 9649.47 & 624.43 & 275.70 & 5.86 \\
\hline 27 Groundnut & 83 & 114167.51 & 71937.63 & 1375.51 & 866.72 & 6.41 \\
\hline 28 Wheat & 27 & 2433.88 & 1345.50 & 90.14 & 49.83 & 2.07 \\
\hline 29 Bambaranut & 92 & 117890.40 & 71856.95 & 1281.41 & 781.05 & 15.72 \\
\hline 30 Sesame & 40 & 21366.29 & 10555.50 & 534.16 & 263.89 & 11.16 \\
\hline 31 Groundnut & 82 & 84120.77 & 53507.80 & 1032.16 & 652.53 & 7.81 \\
\hline 32 Wheat & 25 & 2486.34 & 1468.44 & 99.45 & 58.74 & 2.54 \\
\hline
\end{tabular}


Table 5: K-value for Sesame, Groundnut, Wheat, and Bambaranut, weeks after harvesting in Kogi State University, Anyigba.

\begin{tabular}{lllllll}
\hline Crops & 3 Weeks & 6weeks & 9weeks & 12 weeks & average & SE \pm \\
\hline Sesame & 0.46 & 0.46 & 0.46 & 0.46 & 0.46 & 0.04 \\
Wheat & 0.53 & 0.53 & 0.53 & 0.53 & 0.53 & 0.06 \\
Groundnut & 0.62 & 0.62 & 0.62 & 0.62 & 0.62 & 0.01 \\
Bambaranut & 0.64 & 0.64 & 0.64 & 0.64 & 0.64 & 0.02 \\
\hline
\end{tabular}

Table 6: The Regression equation for calculating Leaf Area for each treatment (Sesame, Wheat, Groundnut, and Bambaranut)

\begin{tabular}{|l|l|l|}
\hline Treatments & $\begin{array}{l}\text { Regression equation } \\
\text { (Simple and multiple) }\end{array}$ & $\left.\mathbf{( R}^{\mathbf{2}}\right)$ \\
\hline Sesame & $\mathrm{Y}=1563.632+0.409 \mathrm{x}_{1}$ & 0.861 \\
& $\mathrm{Y}=1563.632+0.409 \mathrm{x}_{1}-45.734 \mathrm{x}_{2}$ & \\
\hline Groundnut & $\mathrm{Y}=3175.794+0.611 \mathrm{x}_{1}$ & 0.991 \\
& $\mathrm{Y}=3175.794+0.611 \mathrm{x}_{1}+56.820 \mathrm{x}_{2}$ & \\
\hline Wheat & $\mathrm{Y}=-1106.704+0.509 \mathrm{x}_{1}$ & 0.940 \\
& $\mathrm{Y}=-1106.704+0.509 \mathrm{x}_{1}+135.239 \mathrm{x}_{2}$ & \\
\hline Bambaranut & $\mathrm{Y}=162.603+0.615 \mathrm{x}_{1}$ & 0.981 \\
& $\mathrm{Y}=162.603+0.615 \mathrm{x}_{1}+15.677 \mathrm{x}_{2}$ & \\
\hline
\end{tabular}

$\mathrm{X}_{1}=$ Length and breath

$\mathrm{X}_{2}=$ number of leaves.

\section{DISCUSSION}

Linear measurement and graph methods: - k-coefficient for the determination of leaf area at 3, 6, 9 and 12 weeks for Sesame, (Sesame indicum), Groundnut (Arachis hypogaea), Wheat (Triticum aestivum) and Bambaranut (Vigna subterranea) where found to be $0.46,0.62,0.53$ and 0.64 respectively. K- value of $0.46 \pm 0.04,0.62 \pm 0.01$, $0.53 \pm 0.06$ and $0.64 \pm 0.02$ are derived from these four crops sesame, Groundnut, Wheat and Bambaranut respectively, to the matter of fact the value of Groundnut and Bambaranut $(0.62 \pm 0.01)$ and $(0.64 \pm 0.02)$ respectively are more accurate and appropriate than the use of that Sesame and Wheat $(0.46 \pm 0.04)$ and $(0.53 \pm$ $0.06)$ respectively. Since lower $\mathrm{SE} \pm$ values indicate higher precision, these coefficient agrees with other crops such as Okra, Jute (chaudhari and Patra, 1972), Soybean (Weisman and Bailey, 1975) etc. The relative change in the K-value obtained for all the crops with sampling period agreed with studies carried out by Marshal (1968) who observed that k-values changes during plant growth and along with changes in the environmental condition.

In this Research work also, leaf area and leaf number values of all the four (4) crops where tailored into a linear regression analysis separately as well as combined data. However, it shows significant improvement over the use of linear measurement, these agree with the works of (Bhalt and Chanda, 2003).

The product of leaf length time maximum and leaf width was associated more closely with actual leaf area than was either length $\mathrm{x}$ width alone.

\section{CONCLUSION}

From the investigation, the following conclusions were arrived at:

1. In order to reduce or eliminate the drudgery associated with leaf area determination using graph-tracing method, a length $\times$ breadth method multiplied by a coefficient $(\mathrm{K})$ is hereby advocated. The K-coefficient for the following crops were tentatively determined during the course of the experiment Sesame 0.46 , Groundnut 0.62, Wheat 0.53 and Bambaranut 0.64 .

2. To improve on the efficiency of L X B measurement, a regression equation for the crops above were equally determined:
a. Sesame $\left(\mathrm{Y}=1563.632+0.409 \mathrm{x}_{1}\right.$
$\left.\mathrm{Y}=1563.632+0.409 \mathrm{x}_{1}-45.73 \mathrm{x}_{2}\right)$
b. Groundnut $\left(\mathrm{Y}=-3175.794+0.611 \mathrm{x}_{1}\right.$
$\left.\mathrm{Y}=3175.794+0.611 \mathrm{x}_{1}+56.825 \mathrm{x}_{2}\right)$
c. Wheat $\left(\mathrm{Y}=376.084+0.265 \mathrm{x}_{1} \mathrm{Y}=376.084+0.265 \mathrm{x}_{1}-4.559 \mathrm{x}_{2}\right)$, and
d. Bambaranut $\left(\mathrm{Y}=162.603+0.615 \mathrm{x}_{1} \quad \mathrm{Y}=162.603+0.615 \mathrm{x}_{1}+15.677 \mathrm{x}_{2}\right)$ respectively during the period of the work.

3. It is hoped that with the k-coefficient and the regression equation above, the usual destructive method of determining leaf area will be reduced if not eliminated completely.

\section{REFERENCE}

Abani, M.S.C (1988) leaf area formulae from estimating leaf area of Okazi (Gnetumafricana) and Nchuanwu

(Ocimumviridis). Journal of Agronomy and crop science 160:18-182 
Boote K. J. J. W Jones, G. Horgenboom, 1988 Research and management application of pnutgro crop growth model proc. Am. Peanut Res. Edu. Soc., 20, 57

Bhatt M and Chanda S. V. (2003). Prediction of leaf area in Phaseolus vulgaris by non-destructive method. India Journal, department of Bio. Sci. Saurashika University, Rajkot 360005.

Chaudari B. B and Patra A. P (1972) Note on rapid method of determining leaf area in tossal jute. India Journal Agriculture Sci. 44, 1142-1143.

Enoch H. Z., R. G Hurd, (1979). The effect of elevated CO2 concatenation in the atmosphere in plant transpiration and water use efficiency: A study with potted carnation plants. Int. J. Biometer... 23, 343- 351.

Guo; D. P; Sun, Y. Z. estimation of leaf area of stem lettuce (Lactuca sativa varangustana) from linear measurements. India Journal of Agric. Science, v71, n. 7, p. 483-486, 2001.

Kvet, J. \& J.K. Marshall. (1971). Assessments of leaf area and other assimilating plant surfaces. Z.sesta'kjc, and p.g. jarvis, The Hague, The Netherlands. p. 517-574.

Leith J. H., J. P. Reynolds, H. H. Rogers, (1986). Estimation of Leaf Area of soybeans grown under elevated carbondoxide levels field crops Res., 13, 193-203

Manivel, L; Weaver, R. J Biometric correlation between leaf area and length measurement of 'Grenache' grap leaves. Hort. Science, v. 9 n.1, page 27-28. (1974).

Marshall J. K. (1968). Methods of leaf area measurement of large and small leaf samples. Photosynthetica 2:4147.

Montgeomery E. G., (1911), correlation studies in corn, Nebraska Agr. Exp. Sta. Annu. Repr. 24, 108-159 Robbins, S.N and Pharr, D.M. (1987). Leaf Area prediction models for cucumber from linear measurements. Hort. Science 22(6): 1264-1266.

Rouphael. Y, River C. M, (ARDARELLIM, FA-NASCAS COLLAG, (2006). Leaf area estimation from linear measurements in zucchini plants at different ages. Journal of Hort. Sci. and biochtechnology. 81(2), 234-241

Robbins, S.N and Pharr, D.M. (1987). Leaf Area prediction models for cucumber from linear measurements. Hort. Science 22(6): 1264-1266.

Speaskhah A.R 1977. Estimation of individual and total leaf areas of safflowers. Agro. J. 69:783-785.

Wiersma J. V and Bailey, T. B (1975). Estimation of leaflet, trifoliate, and total leaf area of soybeans, Agronomy Journal, 67:26-30. 